conclude that the second hydrogen atom is provided by the enzyme and not by an $\mathrm{H}_{3} \mathrm{O}+$ ion from the solution.

The last three papers at the meeting were concerned with iron porphyrin systems. P. George and G. I. H. Hanania (Cambridge) discussed titration data for myoglobin derivatives, concluding that only one hæm-limited acid group is present. Q. H. Gibson (Sheffield) and F. J. W. Roughton (Cambridge) described work on evaluating velocity constants for the addition of four carbon monoxide molecules successively to the four iron atoms of the hæmoglobin molecule, and similar equilibrium constants with oxygen. The solutions for the equations were obtained using electronic computation. In the absence of differences in reactivity, the velocity constants should be in the ratios $4,3,2$, 1, where 1 refers to addition of the fourth molecule. In fact, the first three constants do not vary much from this expectation, but the fourth constant is enhanced eighty-fold. Gibson described the experimental method used as an adaptation of the flash photolysis technique of Norrish and Porter. B. Chance (Pennsylvania) described work on determining pseudo first-order velocity constants for the steps of the cytochrome chain occurring within the cell,

$\mathrm{O}_{2} \stackrel{k_{1}}{\rightarrow}$ cyta $_{3} \stackrel{k_{3}}{\rightarrow}$ cyta $\stackrel{k_{5}}{\rightarrow}$ cytc $\stackrel{k_{7}}{\rightarrow}$ cytb $\rightarrow \mathrm{fp} \rightarrow \mathrm{DPN} \rightarrow \mathrm{S}$ where fp denotes flavoprotein. Using different wavelengths, it was possible to follow the concentrations of the individual components by spectrophotometric means, and Chance concludes that there is a graded series of reaction-rates from left to right along the chain. This fact must be taken into account in any proposed mechanisms for electron transport. Work was also described with nitrate as oxidizing agent and with photosynthetic systems.

It has only been possible to mention points from each paper in the above brief account, and reference to the lively discussions which followed the papers has had to be omitted. The Faraday Society is to be congratulated on its foresight in bringing together biochemists and physical chemists in what has proved to be one of the most stimulating discussions in recent years.

D. D. Erey

\section{PULMONARY CIRCULATION AND RESPIRATORY FUNCTION}

\section{SYMPOSIUM IN DUNDEE}

$\mathrm{D}$ URING September 15-16, Queen's College (University of St. Andrews), Dundee, organized a symposium on "Pulmonary Circulation and Respiratory Function", which was probably the first of its kind to be organized by a university institution. It was an interesting experiment because the papers read covered a wide range of subjects and the audience was drawn from a wide range of interestsnamely, physicians and surgeons, pathologists, physiologists and applied physiologists. The interest taken in the symposium, to judge from the size and enthusiasm of the audience, was in large part due to the development during recent years of human cardio-respiratory studies all over the world. Much of the work discussed has not yet been adequately assessed from the point of view either of its scientific reliability, or its value in assisting in diagnosis.
Dr. de Burgh Daly (Institute of Animal Physiology, Cambridge) opened the programme with a paper on "Pulmonary Vasomotor Nerve Activity and its Possible Functional Significance". He pointed out that a great deal of careful experimental work on animals is needed to demonstrate the existence of changes in pulmonary vascular resistance due to the action of vasomotor nerves. Valid conclusions can only be reached from the results of animal experiments where factors such as the pulmonary ventilation and circulation can be controlled adequately. Without these precautions, passive changes in pulmonary flow, pressure and resistance may obscure the demonstration of active vasomotor changes. The demonstration of vasomotor responses, as Dr. Daly remarked, does not imply that they play any part in the responses of the intact animal. The conditions of these experiments are often highly artificial. In the human subject, the control of all the variables is so difficult a task that great care should be exercised in drawing any conclusions about the existence of an independent control of the pulmonary blood vessels. Even in animal experiments, the site of action of pulmonary vasomotor fibres is uncertain.

Dr. K. W. Donald (Department of Medicine, Birmingham) gave a paper on "The Pulmonary Circulation in Health and Disease", from which one gathered that the difficulties in designing appropriate experiments, to which Dr. Daly directed attention, must apply also to experiments on man. For example, though there is agreement that the pulmonary vascular resistance to blood flow is small, the effect of exercise on the resistance of the blood vessels is in dispute even in healthy subjects. Some workers consider that the resistance decreases during exercise, whereas others find that the pulmonary vascular bed acts passively in conducting blood. On this matter, there appears to be no agreement about the facts, so it is superfuous to consider whether any question of vasomotion is involved. Dr. Donald concluded that there is as yet no clear evidence of vasomotor activity in human lungs. The problems of physiology posed by disease are numerous and largely unsolved, and some of these were reviewed.

Prof. A. A. Liebow (Yale) stressed the importance of the bronchial arteries, the azygos and other systemic veins in the circulation. His experiments showed that it is possible to ligate the pulmonary arteries and veins and yet have a collateral circulation of oxygenated blood (the extent of which increased in the course of a few months) adequate to maintain life. He demonstrated these points with the aid of casts of the blood vessels and suggested that his experiments may have some application in the treatment of certain developmental abnormalities of the heart and large vessels, and in coronary occlusion. Sir Russell Brock (Guy's Hospital, London) directed attention to the studies which have been made on the physiology of the infundibulum of the right ventricle. Clinical observation both before and at operation in cases of Fallot's tetralogy, for example, make it essential that detailed information should be available about the conditions existing in the infundibulum before a successful operative result can reasonably be expected. He illustrated his thesis by reference to a number of clinical cases.

Prof. J. Gough (Welsh National School of Medicine, Cardiff) reported on the results of post-mortem examinations made in his Department on Welsh coal miners. There is a high incidence of deaths attributable to cor pulmonale and massive pneumoconiosis. 
Prof. Gough described the vascular changes in the lungs in this disease and also indicated the value of studying the grosser pathology of the lungs with the aid of paper-mounted sections. Prof. P. R. Allison (Oxford) described his technique of studying left atrial pressures by puncture of the atrium with a needle inserted down a bronchoscope. His objective was an attempt to distinguish, on the basis of the pressure tracings he obtained, between cases of mitral stenosis and mitral incompetence. The results showed a sharp separation between the two groups, but this clear-cut result (as became apparent in the later discussion) may have been in part due to the selection of patients for a surgical opinion. The view was expressed by Dr. P. Wood (Institute of Cardiology, London) that the results might well have been less clear if an unselected series of cases of disease of the mitral valve was studied. Prof. A. C. Lendrum (Queen's College, Dundee) described his studies on the histology of the small arteries of the lungs in mitral stenosis. The deposition of fibrin in the vessel walls and the distortion of neighbouring nuclei resemble the changes seen in other diseases affecting different organs of the body. He attributed these changes in the lungs to a raised pressure in the pulmonary artery and illustrated them with most pleasing colour photomicrographs.

The discussion of all these papers delivered on the first day of the symposium did not serve to increase our knowledge of the mechanisms involved in the many and complicated effects discussed by the principal speakers, except, perhaps, the contribution of Dr. G. de J. Lee (St. Thomas's Hospital, London), who stated that appropriate measurements made during a Valsalva manœuvre indicate the existence of vasomotor phenomena in the lungs.

On the second day of the symposium, Dr. G. S. Dawes (Nuffield Institute, Oxford) described his experiments on the pulmonary function of new-born lambs, and the changes which take place during the first fow hours of life. His observations show the importance of arterio-venous anastomoses (for example, patent ductus arteriosus) in the new-born lamb, which have the effect of tiding it over the period during which its lungs are becoming more distensible and more fully aerated. He emphasized the need for caution in applying his results to babies as we do not as yet know enough about the details of the circulation in the baby immediately after birth. Prof. W. Melville Arnott (Department of Medicine, Birmingham) described a selection of the numerous tests of lung function now available, and assessed their value as aids to diagnosis. Dr. D. V. Bates (St. Bartholomew's Hospital, London) reported on his experiments on gas diffusion studies as an aid to the assessment of lung function. $\mathrm{He}$ concluded that impaired alveolo-capillary diffusion is probably best revoaled by a study of the 'diffusing capacity' of nitrous oxide. It is difficult to feel convineed about this, because one would imagine that diffusing capacity and ventilation of the alveoli are in some degree interdependent, and his method of calculating the diffusing capacity certainly does not take into account any ventilatory factor. Dr. L. G. C. E. Pugh (London) deseribed the numerous devices (volumecycled and pressure-cycled) now used for maintaining artificial ventilation for long periods. This com. munication had much topical interest in view of the present rise in incidence of poliomyelitis. Prof. I. Donald (Department of Midwifery, Glasgow) described a patient-cycled respirator which he has used successfully for assisted respiration in new-born babies. His physiological observations seomed to support some of those described by Dr. Dawes.

The discussion on the papers delivered on the second day of the symposium was noteworthy for two reasons. On one hand, it was clear that workers, conscious of the difficulty of human experimentation, were anxious to discover more about the physiological basis of the various tests of pulmonary function. On the other hand, a noteworthy contribution by Dr. R. Coope (Liverpool) reminded one that, in general, the tests of function which had been discussed had, as yet, only a limited application as aids to diagnosis. The symposium was a success both on the academic and the social sides. Queen's College went to great lengths to make the stay enjoyable, and it is no exaggeration to say that all the members of the symposium returned home refreshed in mind and body.

J. L. D'Strva

\section{READING TECHNICAL COLLEGE}

T M THE QUEEN MOTHER opened the 1. V1. new Technical College of the County Borough of Reading on October 26. This College was first foreshadowed by various Science and Art classes (under the South Kensington regulations); and these classes, which were already being maintained in $\mathbf{1 8 8 2}$ by the local authority of Reading, themselves arose on foundations laid earlier by various individuals of vision and vigour. By 1892 a new University Extension College, associated with Christ Church, Oxford, had come into being in Reading and had incorporated the former Science and Art classes.

Eventually, the University College received its charter - to become the University of Reading of to-day-but additional evening classes for local students were continued without break for more than fifty years. Thus, by tradition-and no less by the close co-operation of to-day-important and enduring links have been forged between gown and town. During that same half-century, classes for younger students were also being developed at junior evening institutes by the local authority at Reading.

In 1946 the local authority--having already decided to provide a new technical college, and having acquired a building site-recovered from the University full responsibility for evening courses in engineering, building and commerce; and after a transitional session, the new Technical College organization came into being in September 1947. Its first task was to co-ordinate the existing senior and junior evening classes and to provide for their unified direction in the future. The University continued to provide accommodation (and is still so doing), but demand grew rapidly and the local authority found supplementary accommodation at some thirty additional places-thanks in particular to assistance from industry, schools, the Royal Berkshire Hospital, the public libraries, and various undertakings.

The second objective was the development of a service no longer restricted only to evening-work. Lack of accommodation for day-work was a serious difficulty.

The range of local need wais wide. Reading is characterized not by any one predominating industry but by a wide spread of interest. Needs were also urgent, and the authority adopted a bold policy in an endeavour to meet them by compromise, adaptation and by co-operation willingly given on all sides. 